\title{
Monitoring and Evaluation Framework for Veterinary Policy: A Case of Veterinary Services in South Sudan
}

\author{
Salah Khatir Jubarah", *, Isaac Aleardo Paul ${ }^{2}$ \\ ${ }^{1}$ Department of Animal Production, School of Natural Resources and Environmental Studies, University of Juba, Juba, South Sudan \\ ${ }^{2}$ DG State Ministry of Agriculture, Fisheries and Animal Resources, Torit, South Sudan
}

Email address:

sjubarah@yahoo.co.uk (S. K. Jubarah), shankok60@yahoo.co.uk (I. A. Paul)

${ }^{*}$ Corresponding author

\section{To cite this article:}

Salah Khatir Jubarah, Isaac Aleardo Paul. Monitoring and Evaluation Framework for Veterinary Policy: A Case of Veterinary Services in South Sudan. Science Journal of Business and Management. Vol. 9, No. 1, 2021, pp. 1-14. doi: 10.11648/j.sjbm.20210901.11

Received: November 30, 2020; Accepted: December 29, 2020; Published: January 12, 2021

\begin{abstract}
Effective and efficient veterinary services in implementing specific disease control measures and disease surveillance, entails monitoring and evaluation system to be integrated into its budgeted policy framework and strategic plan, a system that keeps the directorate of veterinary services in a mode of action-reflection-action. The guiding principles for the envisaged monitoring and evaluation should include, identification and establishment of veterinary services baseline data; adaptation of result-based decisions and management. While it address measurement of performance, data collection and analysis, reporting, reviews and institutional arrangement. The operationalization of monitoring and evaluation framework for the directorate of veterinary services is to be based on the logical approach of inputs, process, output, outcomes and impact indicators. The collected data on each indicator should be analyzed and summarized in the progress reports of the directorate and be reviewed periodically. However, veterinary health projects and nongovernmental organizations should develop their own indicators in a logical frame. Standard data collection and reporting system have to be developed by key stakeholders, however, animal health survey may be disaggregated. Monitoring and evaluation framework for veterinary policy identifies sources for data generation. It suggest that in absence of baseline data, a pilot survey may be undertaken, and that veterinary policy may be assessed under a join implementation review, animal health expenditure review, budgetary and development fund reviews. However, the envisaged monitoring and evaluation framework emphasizes duties and responsibilities of the directorate of veterinary services in generating a quality data, and in establishment of a unit for veterinary statistic which fosters information culture and promote information demand. Furthermore, it undertake progress review, effect prediction and identification of essential policy adjustment, as well as, it measures progress and it determine as to whether veterinary services and animal health actors are meeting their goals or not.
\end{abstract}

Keywords: Policy, Monitoring and Evaluation, Veterinary Services, Indicators

\section{Introduction}

The ruminant livestock population in the Republic of South Sudan was estimated to be approximately 40 million animals. This represent an investment opportunity of worth 0.55 United States Dollars per head per annum. Comparing South Sudan's livestock population with its fairly low human population and vast land-mass and in terms of livestock asset value. Republic of South Sudan ranks the highest per capita holding country in Africa, whilst its national herd structure of $70 \%$ females provides high potential for increase in livestock productivity [1]. Hence, the Ministry of Animal Resources and Fisheries
(MARF) of South Sudan have developed a National Veterinary Policy (NVP) that will ensure sustainable utilization of these vast livestock resources. Imperatively, implementation of such policy entails monitoring and evaluation framework to be developed and exercised, essentially, as a tool for achieving organizations strategic objectives and to ascertain success [2, 3]. A framework that assess veterinary policy performance against a set of identified strategic issues, objectives and indicators, such that the animal resources sector of the economy is better utilized and with a positive-change in the situations which were identified as problematic. However, in achieving success with monitoring progress in delivery of veterinary services, monitoring and evaluation activities has to 
be conceptualized, prioritized and supported by the relevant concerned leadership [4].

Monitoring and evaluation framework for veterinary policy has to be incorporated as part and parcel of the budgeted policy framework and strategic plan of the national Directorate of Veterinary Services (DVS). The budgetary allocation for the plan was consistent with achievement of the stated goals. The envisaged monitoring and evaluation of NVP should serve as a system that: review progress, identify challenges or changes (in planning or implementation) and make the necessary adjustment. However, the sole purpose of having national veterinary policy performance assessment, is to keep the National Directorate of Veterinary Services (NDVS) in a mode of action-reflection-action, as well as, empowered to act in an informed and constructive way.

\section{Methodology}

The key approach to monitoring and evaluation of the national veterinary policy is an informed-participatory process. All key stakeholders should be involved in the design, implementation and reporting on monitoring and evaluation and when clarifying scope, purpose, intended use, audience and budget for evaluation [5]. Equally, a blend of quantitative and qualitative approaches is often recommended, with sufficient evidence suggesting that qualitative approaches (e.g., outcome harvesting) are essential [6]. However, the main attributes of this process include, but not limited to the following:

I. Simplicity and clarity;

II. Discussion of issues with the stakeholder;

III.Informed participation "all are clear of their involvement and why [5];

IV. Deliverance of efficiency, effectiveness and impact (EEI), and

V. Management is actively involved and should be innovative "not business as usual exercise".

Throughout policy implementation or services delivery, data would be systematically collected with a hindsight to improve efficiency and effectiveness of the policy or plan. The actual impact would be compared against a set strategic plan, in formative and summative manner while looking at, what are set out to be done and why? What have been accomplished? and how the achievements are accomplished and if not why?. The first part of adapted methodology for monitoring and evaluation of the national Directorate of Veterinary Services encompasses firstly, documentation review and collection of baseline data and stakeholder and situational analyses of the National Directorate of Veterinary Services that forms a critical input in development of the framework. Review of relevant national strategies and policy documents which include the MARF policy framework and strategic plans and its budgeted strategic plan for the Directorate of Veterinary Services [1], Draft document on National Veterinary Plan [7], Recommendations of the Livestock and Fisheries Conference [8], Animal Health Baseline Survey [9], the Office International des Epizooties
(OIE) documents [10], National Agricultural and Livestock Extension Policy and various stakeholders including nongovernmental organizations (NGOs) [11-13]. Then followed by determination of key indicators for monitoring and evaluation process; collections of Information pertinent to the targets; development of a structure for analysis; data organizations (targets or objectives); identification of patterns, trends and interpretations, findings and conclusion (the way forward or recommendations).

\section{Directorate of Veterinary Services}

The Directorate of Veterinary Services (DVS) in South Sudan is responsible for preparing and enforcing laws, which govern livestock diseases control and eradication, as well as, the safety of food stuff of animal origin. DVS deliver services through government veterinarians, private sector veterinarians and community-based animal health workers (CAHWs). In safeguarding public health, veterinary services are required to track animal diseases that are transmissible to humans, and the private sector is expected to provide similar veterinary services. However, disease surveillance and control is the sole responsibility and core function of the Ministry of Animal Resources and Fisheries.

The role of NDVS, its structure, statement of vision, mission and core values are documented in the "MARF's policy framework and strategic plans" [1], while its strategic objectives are:

I. To provide effective veterinary services and implement specific disease control measures on behalf of livestock-owning communities in South Sudan;

II. To provide effective public health safety and control of selected diseases of public health importance in South Sudan;

III. To ensure effective livestock diseases surveillance and reporting system operating for South Sudan, and

IV.To improve laboratory diagnostic capacity for routine epidemio-surveillance analysis of priority diseases.

The plans also, coordinates and streamlines development assistance in the livestock and animal health sector, as well as, it recognizes the importance of CAHWs in effective delivery of veterinary services.

\subsection{Veterinary Services Stakeholders and SWOT Analysis}

Satisfying the needs and working effectively with stakeholders are central to the effective performance of NDVS. As such it is necessary to fully document the different stakeholders. Table 1, presents analysis of the stakeholders for livestock development, identifying who they are, what services NDVS provides to them and what are their expectations, as well as, what NDVS expect from them [7].

The scanned environment in terms of "Strengths, Weaknesses, Opportunities and Threat" (SWOT) analyses are presented in Table 2, it was used to audit the internal capabilities and weaknesses of the MARF DVS and to understand the environment (opportunities and threats) of the State in terms of livestock resources [7]. 
Table 1. Veterinary Services Stakeholder Analysis.

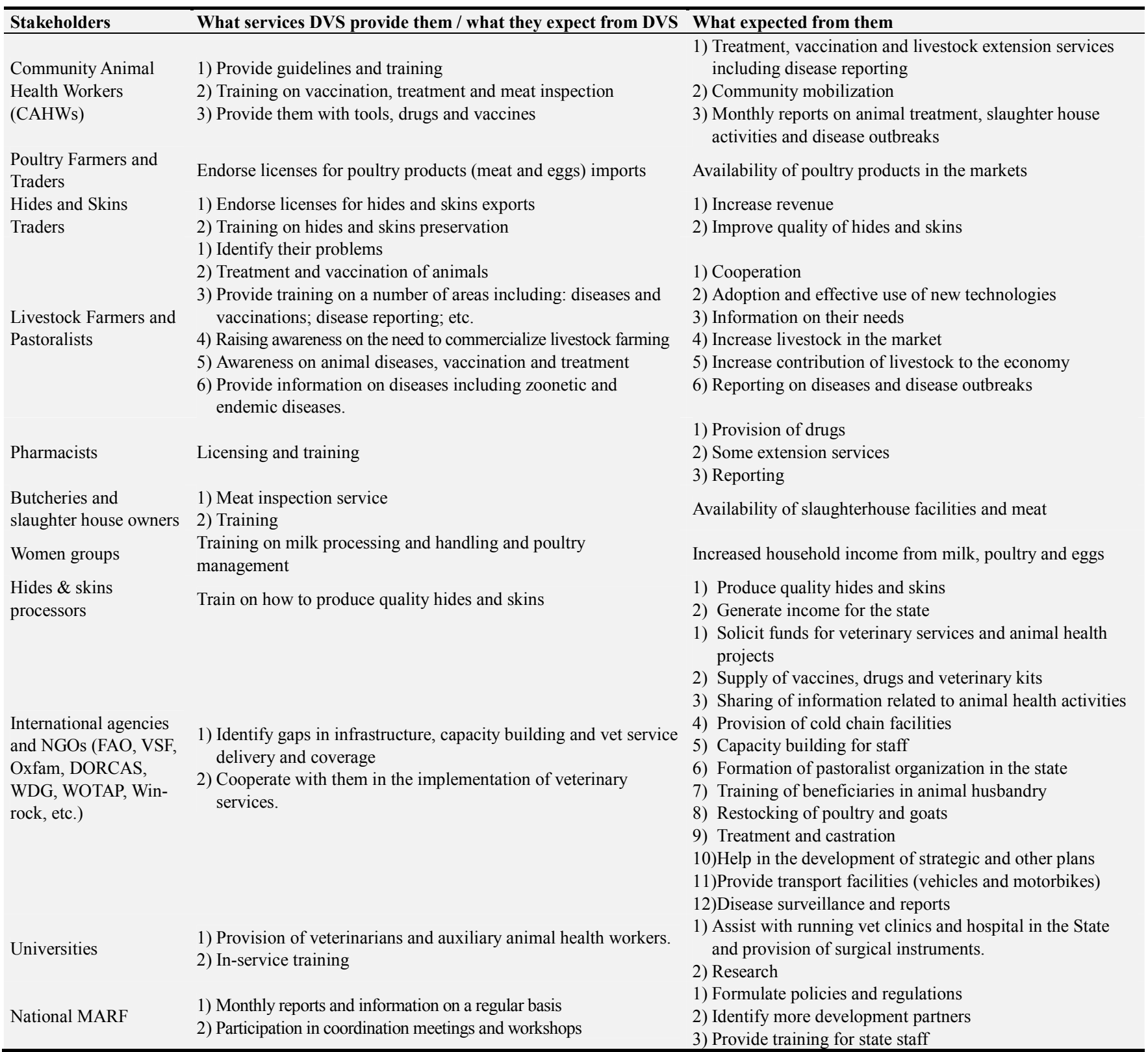

\subsection{Animal Health Baseline Survey}

The key findings of the 2010 baseline survey [9] on status of livestock production depicted that South Sudan rural livestock farming household has low production across animal resources sectors, that is to say, livestock, fisheries and apiary, low farming knowledge and skills, inadequate labor, limited access to service providers like CAHWs, veterinarians, livestock and extension officers. There was general lack of adequate access to production inputs, output markets, improved technology and related support services including rural finance, communication and feeder roads.

Generally, livestock production system and distribution are associated with agro-ecological zones. The agro-pastoralists are the inhabitants of the flood-plains (the Nilotics: Dinka,
Nuer, Collo and others). Whilst the pastoralists inhabit the slopes of eastern-hills and mountains (Murle, Toposa and Boya), their productionsystem was characterised by seasonal migration (trans-human). However, inhabitants of the greenbelt are practicing subsistent-agriculture and herding few livestock.

Over the last ten years now, an estimated rural household annual income from the agriculture and livestock production, among others, was 2,839.79 SSP. This reveals that majority of the South Sudanese earns less than half a dollar a day. However, the benchmark indicators generated from this survey (Table 3) could be serving as information base for animal resources to assess effectiveness and efficiency of project in meeting its outcomes and impact or program delivery. 
Table 2. SWOT Analysis - Directorate of Veterinary Services.

\section{STRENGTHS}

1) Independent ministry separate from the Ministry of Agriculture

2) 6 refrigerators and one cold room under construction

3) A number of qualified staff including 8 veterinary doctors and 10 technicians.

4) Political good will and support and a very committed staff.

5) Importance of animal disease control to food security, incomes and trade

6) Importance of public health and food safety to national and foreign consumers

7) Accumulated past experience and knowledge and well developed strategies to control animal diseases

8) Strong networking with CAHWs in service delivery

9) National extension policy (NALEP) to guide extension in South Sudan has been developed and is awaiting Cabinet approval.

10) National MARF Strategy and Policy Framework in place which provides direction to states.

11) Lack of extension materials and capacity to prepare them

12) Good internal coordination in the DVS

13) Good coordination between SMARF, MARF and NGOs

14) Good coordination and cooperation between directorates

15) Good team work within the Directorate

\section{WEAKNESSES}

1) Inadequate number and skills of staff including vet doctors, technicians, stock persons, and animal health auxiliaries.

2) Poor infrastructure including lack of office facilities and equipment (furniture, computers, etc.)

3) Lack of a diagnostic lab at the States and counties

4) Inadequate transport facilities

5) Poor cold chain facilities in counties.

6) Inadequate number of vet clinics at states and counties

7) Inadequate drug, vaccines, surgical instruments and other vet tools

8) Non-existent livestock extension services

9) Weak disease surveillance and reporting system

10)Poor communication system from counties to the HQs

11)Lack of effective livestock disease control strategy and program for the State

12)Lack of veterinary reference and other materials for staff in the ministry

13)Inadequate funding

14)No research capacity to support the development of the subsector

15)Poor capacity and articulation of animal production

16)Inadequate flow of information to the MARF

17)Weak early warning system and response mechanism for disease epidemics and other animal related emergencies

18)Inadequate staff training facilities within South Sudan

19)A significant majority of staff are men.

20)Weak monitoring, evaluation and reporting system

21)Poor accountability for resources from MARF (e.g. Capital Funds).

22)Lack of training including for existing technicians and post graduate training for graduate staff

23)Inadequate salaries and allowances

\section{OPPORTUNITIES}

1) Vast resource base and high potential of livestock

2) Availability of pasture and water

3) Oil revenue to support animal production

4) Significant investment potential and many investors showing interest in the State

5) Relative peace - movements are easier without fear of attack

6) Local and international NGOs and other stakeholders operating in the State and willing to lend support to develop the sector.

7) Availability of active CAHWs in remote areas in the State.

8) Food security a top government (RSS) priority

9) Animal demand for animal products within and without South Sudan. In particular, there is a huge market in the Gulf.

10) Existence of qualified persons in South Sudan and the region.

11) Possibility to control and eradicate the most devastating animal diseases to improve health and increase production.

12) Existence of knowledge and expertise in the region and the World.

13) Importance of regular and consistent reporting on disease and animal health status to OIE, FAO, WHO, AU-IBAR, and RECs

14) Government and international policies and agenda e.g. MDGs, etc friendly to achieving food security, poverty alleviation and wealth creation.

15) Information system exists which regularly disseminates livestock prices from selected markets online (by MARF)

16) Existence of training opportunities and institutions in the region and globally.

17) Previous initiatives that can be revived e.g. Marial Bai Dairy Institute, etc.

\section{THREATS}

1) High prevalence of livestock diseases

2) Absence of water and pasture especially in dry season

3) Migration to urban areas by the youth

4) Political interference

5) Low education level

6) High level of unemployment

7) Low level of private sector development

8) High dependency on government for employment

9) Lack of market information which make pastoralists vulnerable to selling at low prices by middle men and brokers who are better informed

10)Inadequate slaughter infrastructure in counties

11)Inadequate quarantine facilities

12)Unauthorized, unlicensed and unhygienic slaughtering of animals

13)Cattle rustling in the state and conflicts between farmers and livestock owners

14)Uncontrolled movement of livestock within and through the state which increased incidence of disease outbreaks.

15)Traditional practices that run counter to the development of the livestock industry including the keeping of livestock for prestige.

16)Poor road network in some counties

17)Inadequate numbers of trained CAHWs and loss resulting from poor supply of vet drugs, inadequate work opportunities and incentives

18)Absence of pasture and water during the dry season.

19)Poor coordination of activities among stakeholders

20)Lack of clear land tenure policy

21)Conflicts of responsibilities between the states and the National Government.

22)Absence of a legal framework for livestock activities in the State

23)Inadequate policy, legal and regulatory framework (control of livestock movements, trade and marketing, etc.)

24)Prices and markets instability

25)International competition through globalization including highly efficient low cost producers from other regions and from those nations that enjoy subsidies.

Table 3. Selected Livestock and Fisheries Benchmark Indicators and Results.

\begin{tabular}{ll}
\hline Rural Agricultural Household Indicators & Baseline Results \\
\hline Livestock & \\
Percentage of households engage in livestock & $57 \%$ Cattle (35), \\
Composition of livestock in households & Sheep (13) and Goats (15) \\
Common Cattle Disease & CBPP \\
Proximity to the nearest extension services & $41-70$ miles \\
Estimated number of cattle in camps & $400-600$ heads \\
\hline
\end{tabular}




\begin{tabular}{ll}
\hline Rural Agricultural Household Indicators & Baseline Results \\
\hline Income from livestock annually & $1,500 \mathrm{SPP}$ \\
Over-all satisfaction on animal health services & $17.4 \%$ fully satisfied \\
Fishery & \\
Households engage in Fishing & $14.2 \%$ \\
Average Number of catches per season & $235.30 /$ rainy season, 198.52/dry season \\
Percentage of fish caught sold to the market & $59 \%$ \\
Fisher type & Commercial(16.4\%) 39.7\% (non-commercial) \\
Over-all satisfaction on the services provided & $14.4 \%$ fully satisfied \\
\hline
\end{tabular}

\section{Rationale for Developing Monitoring and Evaluation Framework for Veterinary Policy}

Approximately, $70 \%$ of South Sudanese are based in the rural areas. They depend to a greater extent on livestock production for their livelihoods. Hence the need for development and commercialization of this vast livestock resources was recognized in the South Sudan Development Plan, as one of the most potential and vibrant areas for sustainable economic growth and poverty reduction. As stipulated in the Comprehensive Africa Agriculture Development Program (CAADP), the Government of South Sudan has pledged to allocate $10 \%$ of annual national budget to agriculture [14] with the aim of attaining $6 \%$ annual livestock growth rate through improvement in veterinary services, this excludes the contribution of the development partners to this sector of the economy. Hence, effective veterinary services are of key importance in enhancing livestock production and productivity as credible support to commercialization of this economic sector.

The NDVS have clearly outlined its strategic objectives, encapsulating the national veterinary policy, envisaged to transform and improve livestock health with subsequent economic growth and poverty reduction. As such it deem necessary that monitoring and evaluation system should be developed and embedded in the National Veterinary Policy for sustainable livestock development and poverty eradication. A system that requires assessment of performance against a set strategic issues, objectives and indicators, such that livestock sector is better utilized in a positive and sustainable manner.

Monitoring and Evaluation Framework for the National Veterinary Policy will provide livestock's beneficiaries and stakeholders with a systematic and periodical feedback on the implementation of the national veterinary policy. The framework provides an early indications of the progress, achievement or failure, such that a timely interventions and adjustment could be undertaken. However, monitoring of NDVS is a process of measuring progress in delivering veterinary services, intimating that the implementation of the national veterinary plan should be undertaken with view of learning and correction at the same time. It should also be seen as continuous assessment of the implementation of national veterinary services in relation to the adapted policy. In another word what was planned and expected as per the strategic objective of DVS, outputs, outcomes and impact on livestock health status, livestock performance and livestock communities (either pastoralist, agro-pastoralists) or livestock beneficiaries.

The performance of veterinary services was to be periodically evaluated and reviewed, however, the effectiveness and impact of the veterinary plan should be assessed in relation to its strategic objectives. In a nutshell, evaluation would be undertaken selectively to review progress, predict effects and identify essential adjustment in the national veterinary plan, which should be based on data collected at monitoring process. The essence is to ascertain as to whether veterinary services including disease surveillance, animal health project, CAHWs and all the strategic issues are on track or not, and what are the lessons learned. It should also answer whether the NDVS and all animal health actors are meeting their goals or not and could it be improved. Monitoring and Evaluation Framework for the National Veterinary Policy should be considered as an integral part of the Budgeted Policy Framework and Strategic Plan of the Directorate of Veterinary Services. Thus, the framework should be seen as a system that: review progress, identify problems (in planning or implementation) and make the necessary adjustment (and difference) or a system that enhances understanding of the trends in services delivery of DVS vis-à-vis food and nutrition security and poverty reduction over time.

The overall objectives of the envisaged National Veterinary Policy Monitoring and Evaluation Framework are to:

I. Outline a system for monitoring and evaluation for the Directorate of Veterinary Services, that will provide information which will enables stakeholders and planners to track progress and making informed decisions;

II. Promote the significance of systematic data collection and utilization of the monitoring and evaluation findings in the Directorate of Veterinary Services delivery;

III. Augment M\&E capacity of DVS/stakeholders in data collection and utilization of the findings, and

IV. Keep the NDVS in a mode of action-reflection-action, informed and empowered to act in an informed, evidenced-based and constructive way.

Monitoring and Evaluation of the National Veterinary Policy (NVP) could be carried-out and guided under the following principles:

I. Identification and establishment of the veterinary services baseline data;

II. Routine M\&E to be integrated into MARF, SMARF and animal health projects such that progress towards goals are measured;

III. Starting with simplicity and from the current animal 
health situation (that serves as benchmarks or the baseline data);

IV. Utilization of the (contemporary and up-to- date) data collection system;

V. Result-based decisions and management are to be adapted;

VI. Facilitating inter-stakeholders co-ordination, as coordination between stakeholders (MARF and SMARF DVS, NGOs, Livestock farmers and communities) are required in veterinary services delivery and in the merger of monitoring and evaluation system to the NVP;

VII. In harmony with other sectors of "Animal Resources and Fisheries" systems of M\&E, and

VIII. Has to recognize the dynamic of livestock industry as a sector of the economy.

\section{Scope of the National Veterinary Policy Framework}

Performance measurement assesses progress in veterinary services delivery toward desired levels of specific activities, outputs, and outcomes [15]. Both data and information systems are necessary for monitoring and evaluation exercise [16] as they link monitoring to reporting, as well as, they incorporate use of impact oriented monitoring methodology [17]. However, the envisaged Monitoring and Evaluation Framework for Veterinary Policy intend to contribute towards achieving objectives of the Directorate of Veterinary Services, through generating a reliable and systematic data, as well as, measurement of the performance of Directorate of Veterinary Services; data collection and analysis; reporting and reviews, and institutional arrangement for the National Veterinary Policy Framework.

\subsection{Veterinary Policy Framework}

Strategic plan for the National Directorate of Veterinary Services (NDVS) has to be monitored and evaluated through set of indicators. Indicators are quantifiable variables that present bases for the assessment of veterinary services within a given timeframe, they have to capture the outcomes or results. Indicators should be easy to monitor and measure performance of the Directorate of Veterinary Services in a quantifiable way, they have to reveal progress or regress in relation to DVS strategic objectives.

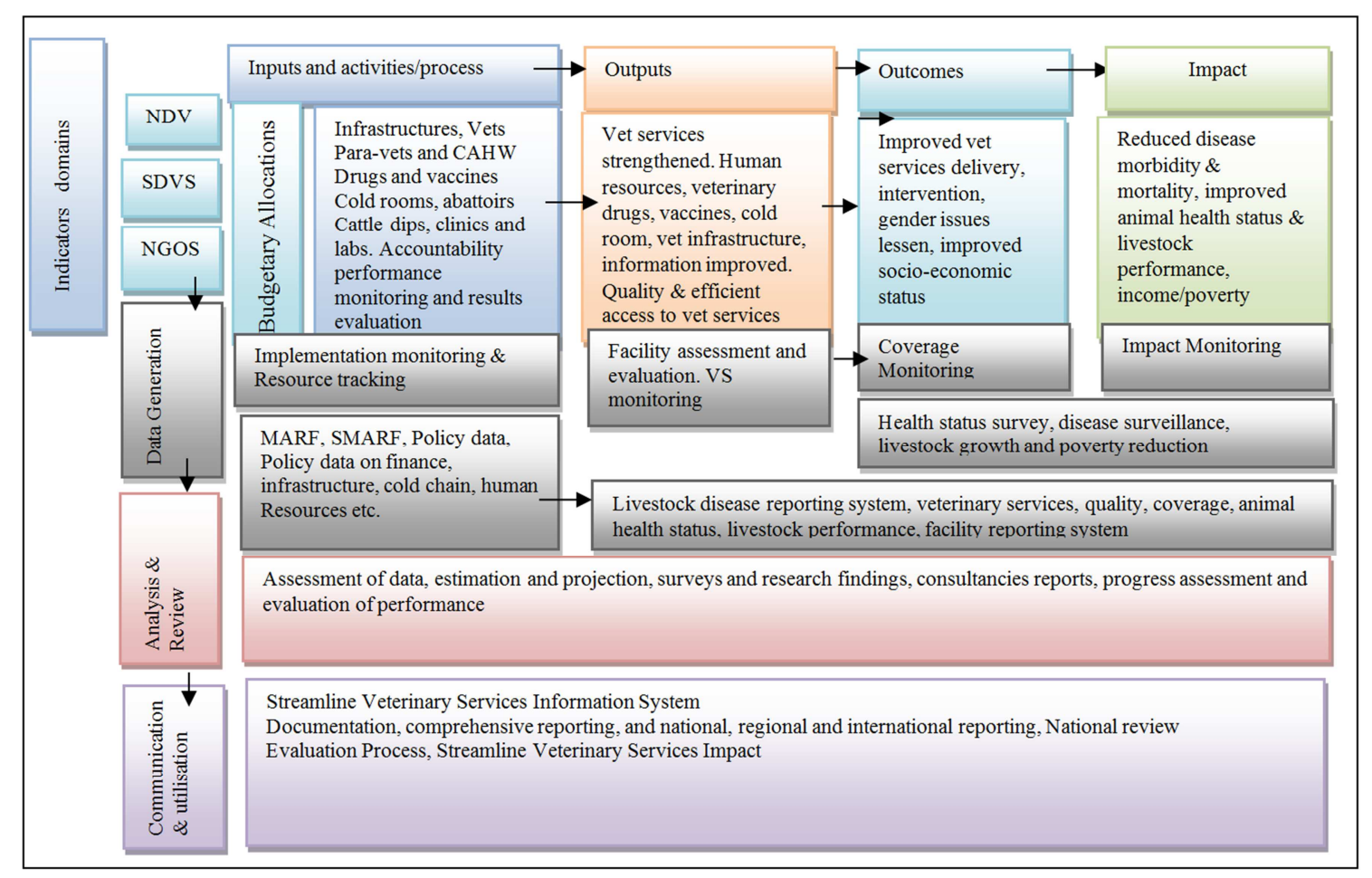

Figure 1. Monitoring and Evaluation of the National Veterinary Services Framework.

The operational framework for National Veterinary Policy is presented in Figure 1, it is formulated to ensure continuity in monitoring and evaluation of objectives of the Directorate of Veterinary Services and is based on the logical approach $[18,19,21]$ of the following indicators:

I. Inputs (are the necessary resources to carry-out program activities)/process (activities carried-out by using inputs);
II. Output (are the specific tangible products and services that emerge from processing inputs, they are necessary to achieve DVS objectives);

III. Outcome (or effect is the actual or intended change in development condition that Veterinary Services are seeking to support), and

IV.Impact (are the broad changes brought about by the DVS or animal health project, is the ultimate result due 
to NVP).

The National Veterinary Policy indicators are first to be developed at the National Directorate of Veterinary Services, as the first level of indicators, developed to measure whether the Directorate of Veterinary Services has attained its strategic objectives and goals or not. While, progress or performance at the states and counties levels, are measured through the state's Directorate of Veterinary Services indicators. Each National Veterinary Services indicator has to take into account the strategic plan and objectives of the states' Directorate of Veterinary Services, which are expected to be in harmony with that of National Directorate of Veterinary Services.

Animal Health Projects could form a third level of indicators. Each national, state or NGOs animal health project may develop its own indicators of progress in relation to its own strategic policy and goals and within the national veterinary policy's objectives and based on the strategic planning implementation log frame of the project in question. The overall framework for the National Veterinary Policy presented in Figure 1, depicts four sets of indicators, the inputs and the outputs indicators, these two sets of indictors are mirroring the capacity of veterinary services. Whilst the output, outcome and impact indicators reflect the livestock or animal health performance as a result of investments in veterinary services and for every set of indictors the sources of data collection either at the level of state, national or animal health projects have to be sought.

The framework (Figure 1) also, associate indicators with the sources of data, and it shows how veterinary services inputs in terms of infrastructure, finance, veterinarians, veterinary technicians, community animal health workers, vaccines, drugs and cold chain just to mention but few are reflected in outputs (delivery of veterinary services), subsequently outcomes and impact utilized health services and improved animal health status. Also, it demonstrates, the performance of veterinary specific interventions (on animal health and certain disease). The framework also illustrates and addresses, the needs for data quality assurance, data synthesis and analysis, results dissemination, as well as, utilization of monitoring and evaluation to inform all the stakeholders including the NDVS and states' DVS.

\subsection{The National Veterinary Policy/Services Indicators}

In the context of the National Veterinary Policy, monitoring and evaluation of the veterinary services entails observations on livestock health status and livestock production performances, with the provision and collection of data, which should indicate whether or not the national veterinary services is making some progress towards achieving its outlined strategic objectives or not (Figure 2). As such, veterinary services' performance indicators are crucial in informing livestock stakeholders about the trend in animal health status vis-à-vis delivery of veterinary services that can be reviewed; the course of action that improves performance of veterinary services, and the status of animal health and livestock health performance and its contribution to livestock growth, food and nutrition security, poverty reduction, pastoralist welfare and the national economy.

To develop indicators for the veterinary services, the outcome statements (which are the actual or the intended changes in animal health conditions that the interventions seek to support and bring about, i.e., a change in the health status or conditions between comparison of outputs and the impact achievement, as the case with improved livestock health, productivity and subsequently increased livestock owners income) as depicted in the strategic planning and implementation matrix of the NDVS [8] are defined in terms of the strategic issues or areas of the DVS (Figure 2) and they include several activities or processes that lead to overall outcome statements matching with the DVS strategic objectives.

As shown in Figure 1, four sets of indicators are to be developed to cover inputs/process, outputs, outcomes and impact. Each indictor should be specific, measurable, achievable, realistic, timely bound and useful. Therefore, the data should be collected on each selected indicator, analyzed and summarized in the DVS progress reports and has to be reviewed periodically. If need be the data could be disaggregated into gender, disabilities, youth etc., and if so then MARFs strategic policy has to incorporate indicators to monitor and evaluate their progress. However, the state indicators of progress should reflect the objectives and goals of the SMARF's DVS as specified in their strategic plan, which should be harmonized and consistent with that of MARF's DVS. The SMARF should measure achievements in relation to the SMARF's DVS objectives as per the state in question.

In the case of monitoring and evaluation of the national veterinary health projects or NGOs, each animal health project has to develop its own indicators in a logical framework that based on policy and budget., and it is preferred to start with the minimum indicators as it makes data collection, analysis and interpretation much easier and doable. The periodical collection of data on DVS performance indicators facilitates effective monitoring of the NVP, analysis and evaluation of the performance trend in the delivery of veterinary services so that the MARF's DVS and all the stakeholders will be in a better position to make the right decisions.

Veterinary services indicators should provide bases for informed decisions and should reveal trends or emerging issues. Furthermore, DVS indicators should aid in identifying strategies that are to be strengthened; help in the analysis of the performance trends; provide quality information for informed decision; establish accountability for the allocated resources (i.e. accountability of SMARF's DVS against their strategic objectives); stakeholders are informed of the progress in delivering veterinary services, lesson learned and identification of interventions areas, and provide systemic evaluation of impact against set target, to check if the program is on the tract or not.

\subsection{Livestock Health Status and Livestock Productivity}

For effective veterinary services in implementing specific 
disease control measures, the shortlisted indicators presented in Tables 1, 2 and 3 could be used to monitor progress of the NDVS towards achieving its strategic objectives [8], as well as, assignment of the expected outcomes to the strategic issues is crucial to performance measurement. However, indicators have to be reviewed periodically such their accuracy are maintained.

A disease outbreak indicator usually measures the frequency at which the outbreaks occur in order to arrive at a measure of rate of a disease incidence, which is an indicative to animal health status and trends, it have a significant implication for livestock productivity $[18,20]$. However, the OIE (World Organization for Animal Health) article 1.3.4.1.4 [10] outlines appropriate information required for selfevaluation of veterinary services of a country and it include: organization and structure of veterinary services, national information on human resources, financial management information, administration details, laboratory services, functional capabilities and legislative support, animal health and veterinary public health controls, quality systems and performance assessment and audit programs.

\begin{tabular}{|c|c|}
\hline Outcome Statement & MARF's DVS Strategic Issues \\
\hline $\begin{array}{l}\text { Improvement in veterinary infrastructure, } \\
\text { Service delivery and cross-cutting issues. Institutional } \\
\text { framework strengthened }\end{array}$ & $\begin{array}{l}\text { Increasing livestock growth rate, food (animal protein) } \\
\text { sufficiency, increase farmer income \& poverty reduction }\end{array}$ \\
\hline $\begin{array}{l}\text { Veterinary equipment, vaccines and } \\
\text { drugs delivered cold room delivered } \\
\text { and established }\end{array}$ & $\begin{array}{l}\text { Ensuring delivery of veterinary equipment, drugs and } \\
\text { vaccines and establishing cold room }\end{array}$ \\
\hline $\begin{array}{l}\text { Important vector-borne diseases, PPP } \\
\text { and CBPP, FMD, RVF and other } \\
\text { emerging diseases under control }\end{array}$ & $\begin{array}{l}\text { Controlling vector-borne diseases, ticks and tick-borne } \\
\text { diseases (ECF), PPP, CBPP, FMD, RVF and other } \\
\text { emerging diseases }\end{array}$ \\
\hline $\begin{array}{l}\text { Livestock Epidemio-Surveillance } \\
\text { System effectively implemented, GIS in use for livestock } \\
\& \text { diseases information }\end{array}$ & $\begin{array}{l}\text { Developing effective and efficient disease surveillance } \\
\text { systems and procedures, using GIS inclusive }\end{array}$ \\
\hline $\begin{array}{l}\text { Animal health certification availed } \\
\text { and border check points established }\end{array}$ & $\begin{array}{l}\text { Establishing border check points and animal health } \\
\text { certification }\end{array}$ \\
\hline $\begin{array}{l}\text { Diagnostic laboratories strengthened, equipment and } \\
\text { consumables procured }\end{array}$ & $\begin{array}{l}\text { Strengthening diagnostic laboratories, purchasing Lab. } \\
\text { equipment and consumables -States and National labs }\end{array}$ \\
\hline $\begin{array}{l}\text { Meat and milk hygiene improved. } \\
\text { Abattoirs and meat outlets constructed }\end{array}$ & $\begin{array}{l}\text { Improving meat and milk hygiene, construction of } \\
\text { abattoirs and meat outlets }\end{array}$ \\
\hline $\begin{array}{l}\text { MARF/SMARF staff trained on database management. } \\
\text { Diagnosticians and lab technicians are trained }\end{array}$ & $\begin{array}{l}\text { Training of staff on database management and for } \\
\text { diagnosticians and lab technicians }\end{array}$ \\
\hline $\begin{array}{l}\text { Rabies surveyed \& controlled, disease reporting system } \\
\text { operationalised }\end{array}$ & $\begin{array}{l}\text { Implementing rabies surveys and } \\
\text { developing diseases reporting system }\end{array}$ \\
\hline OIE zoning and compartmentalisation protocol assessed & $\begin{array}{l}\text { Assessing the use of zoning and compartmentalization } \\
\text { protocol(OIE) for specific disease surveillance and } \\
\text { control }\end{array}$ \\
\hline $\begin{array}{l}\text { Awareness campaigns conducted for } \\
\text { VF/ECF/PPR/FMD/HPAI and trypanosomiasis }\end{array}$ & $\begin{array}{l}\text { Conducting awareness campaigns on RVF, ECF, PPR, } \\
\text { FMD, HPAI and trypanosomiasis }\end{array}$ \\
\hline
\end{tabular}

Figure 2. Relationship between MARF's DVS Strategic Issues and the Outcome Statement.

The indicator captures the year in which disease outbreaks occurred over a period of years and the number of disease outbreaks occurring in a year. It should be constructed for a series of different diseases such as Foot and Mouth Disease and Avian Flu (per each state or agro-ecological zones). As for the vulnerability of each state to diseases it should be estimated in terms of the number of diseases outbreaks within a given state or agro-ecological zones in a given time or a season, or in terms of the number of livestock affected by each disease outbreak.

Disease outbreak and disease severity indicators could be used as indicators to monitor incidences of trans-boundary disease (Foot and Mouth Disease). However, the proportion of mortality due to a disease can be used as an indicator of the severity of the attack. Indicators could be constructed or mapped for each state and then for the Republic of South Sudan. The prevalence of each disease can be measured by computing the number of sick and dead animals in proportion to the total number of the livestock population [18].

The set of shortlisted indicators presented in Tables 4 and 5 reveals the efficiency of the Veterinary Services and resource utilization. Efficient Veterinary Services will affect positively livestock growth, trade and profitability and subsequently livestock growth performance. 
Table 4. Shortlisted Indicators to monitor trend in Livestock's Health and Production.

\begin{tabular}{|c|c|c|c|c|}
\hline Indicators & Definition & Unit & What it Measures & Objective/Goals \\
\hline Livestock Growth & Animal Resources' GDP (\%GDP) & $\%$ & Animal Industry growth rate & MARF, CAADP \\
\hline $\begin{array}{l}\text { Livestock Farm } \\
\text { (household Income) }\end{array}$ & $\begin{array}{l}\text { Proportion of livestock farm income/ } \\
\text { livestock farm household income }\end{array}$ & $\%$ & $\begin{array}{l}\text { Average proportion of livestock farm } \\
\text { income } \% \text { of livestock farm household } \\
\text { income/year }\end{array}$ & $\begin{array}{l}\text { MARF MDG, } \\
\text { CAADP, }\end{array}$ \\
\hline Poverty head count & $\begin{array}{l}\text { Percentage of population with income } \\
<1 \$ \text { a day }\end{array}$ & $\%$ & Poverty incidence & MARF, MDG \\
\hline $\begin{array}{l}\text { Animal health } \\
\text { expenditure }\end{array}$ & $\begin{array}{l}\% \text { of annual public spending on animal } \\
\text { health }\end{array}$ & $\%$ & Share of MARF in national budget & $\begin{array}{l}\text { GRSS, MARF, } \\
\text { CAADP }\end{array}$ \\
\hline Livestock Productivity & Per capita holding & $\mathrm{SSP} /$ population & Marginal productivity value & MARF \\
\hline $\begin{array}{l}\text { Diseases surveillance } \\
\text { /CAHW/Diseases }\end{array}$ & $\begin{array}{l}\text { Population of vaccinated livestock, } \\
\text { medicine used/farm household }\end{array}$ & $\begin{array}{l}\% \text { dose per livestock } \\
\text { population /unit }\end{array}$ & $\begin{array}{l}\text { Disease prevalence, growth in livestock } \\
\text { population and production }\end{array}$ & MARF DVS \\
\hline Disease outbreak & Number of disease outbreak incidences & Number & Frequency of disease outbreak & MARF DVS \\
\hline Disease severity & Mortality \% due to disease outbreak & $\%$ & Severity of disease outbreak & MARF DVS \\
\hline $\begin{array}{l}\text { Livestock Yield (meat, } \\
\text { milk and hides and skins) }\end{array}$ & Quantity of animal resources output/LU & Unit/LU & DVS progress/time & MARF \\
\hline $\begin{array}{l}\text { Meat, milk, eggs, hides \& } \\
\text { skin price }\end{array}$ & Trend in food price & $\%$ & $\begin{array}{l}\text { Trend in meat, milk, egg, hide \& skin } \\
\text { supply }\end{array}$ & MARF \\
\hline $\begin{array}{l}\text { Meat, milk, eggs, hides \& } \\
\text { skin import }\end{array}$ & $\begin{array}{l}\% \text { imported animal food value } \\
\text { consumed }\end{array}$ & $\%$ & Livestock products self-sufficiency & MARF \\
\hline
\end{tabular}

\section{Data Generation, Analysis, Reporting and Review}

The efficiency of National Veterinary Services could be assessed through analysis of inputs results (in terms of outputs, outcomes and impact) using core indicators that target the trend in livestock's health status and growth (Tables 3, 4, and 5). However, monitoring and evaluation should first deal with data synthesis, analysis and interpretation.

It is important first to identify the source of data to be collected for a given indicator and secondly, to ascertain the quality of the data which has to be systematic and according to the OIE standards [10]. But for the data quality assurance and reliability, the generated data has to be screened for biasness, non-representativeness and inaccuracies in reporting etc.

\subsection{Data Sources}

The data source can also be generated or expressed in relation to the livestock population as a whole or as an outcome of the veterinary services, livestock health in relation to administrative and operational activities. Animal health research and clinical trials may also be fed into livestock health information system, however, the types of data which could be used for monitoring and evaluation of the DVS performance can be grouped into the following two types of data:

\subsubsection{Directorate of Veterinary Services'Data Type}

This type of data provides information on veterinary services delivery and animal health performance at states, county, boma and the national levels, as exemplified in the following formats:

Table 5. Shortlisted National Veterinary Policy impact, outcome and output indicators.

1.0 Impact indicator

\begin{tabular}{|c|c|c|c|c|}
\hline S/No. & Impact indicator & Reporting Schedule & Data Source and Responsibility & Disaggregation \\
\hline 1.1 & $\begin{array}{l}\text { Livestock and Fisheries GDP Growth Rate } \\
\text { (Livestock Sector of the Economy) }\end{array}$ & Annual & $\begin{array}{l}\text { MARF's Directorate of Planning and the South } \\
\text { Sudan Centre for Census Statistics and Evaluation }\end{array}$ & National \\
\hline 1.2 & Value of Livestock Export & Annual & MARF's Planning, National Bureau of Statistic & National \\
\hline 1.3 & $\begin{array}{l}\text { Pastoralist and Livestock farmers head } \\
\text { count/basic needs poverty line }\end{array}$ & Periodical & MARF's Planning, National Bureau of Statistic & National \\
\hline
\end{tabular}

2.0 Outcome Indicator

\begin{tabular}{|c|c|c|c|c|}
\hline S/No. & Outcome Indicators & $\begin{array}{l}\text { Reporting } \\
\text { Schedule }\end{array}$ & Data Source and Responsibility & Disaggregation \\
\hline 2.1 & Food (animal protein) self-sufficiency & Annual & $\begin{array}{l}\text { MARF's Directorates of VS, Planning, } \\
\text { Animal Production and the MARF's } \\
\text { Capital Fund Expenditure. }\end{array}$ & States and National \\
\hline 2.2 & $\begin{array}{l}\text { Livestock Production and Productivity (Meat, Milk, eggs, } \\
\text { hides and skin) }\end{array}$ & Annual & $\begin{array}{l}\text { MARF's Directorates of Planning, Animal } \\
\text { Production and the MARF's Capital Fund } \\
\text { Expenditure }\end{array}$ & $\begin{array}{l}\text { States, District, National } \\
\text { and Agro-ecological Zones }\end{array}$ \\
\hline 2.4 & Proportion of pastoralists and livestock farmers served by & Periodical & MARF's DVS and SMARF & National and Agro- \\
\hline
\end{tabular}




\begin{tabular}{|c|c|c|c|c|}
\hline S/No. & Outcome Indicators & $\begin{array}{l}\text { Reporting } \\
\text { Schedule }\end{array}$ & Data Source and Responsibility & Disaggregation \\
\hline & livestock extension officer, CAHW, Para-vets and Vets & & & ecological Zones \\
\hline 2.5 & Number of incidences of disease outbreak & Periodical & MARF's and SMARF's DVS & $\begin{array}{l}\text { National, State and counties } \\
\& \text { boma }\end{array}$ \\
\hline 2.6 & Number of disease incidences surveyed & Periodical & MARF's and SMARF's DVS & $\begin{array}{l}\text { National, State, counties } \\
\text { \&boma }\end{array}$ \\
\hline 2.7 & Amount of Vet. Drugs and vaccines used & Annual & $\begin{array}{l}\text { MARF's Directorates of Planning, Animal } \\
\text { Production and the MARF's Capital Fund } \\
\text { Expenditure. }\end{array}$ & National \\
\hline 2.8 & $\begin{array}{l}\text { Proportion of pastoralist and livestock farmers using dip } \\
\text { tank (cattle dip) }\end{array}$ & Periodical & $\begin{array}{l}\text { MARF's Directorates of Planning, Animal } \\
\text { Production and the MARF's Capital Fund } \\
\text { Expenditure }\end{array}$ & National \\
\hline 2.9 & Total lending to livestock sector (by Agricultural Bank) & Annual & MARF's DVS, and SMARF's DVS & $\begin{array}{l}\text { National and Agro- } \\
\text { ecological Zones }\end{array}$ \\
\hline
\end{tabular}

3.0 Output Indicator

\begin{tabular}{|c|c|c|c|c|}
\hline S/No. & Output Indicators & $\begin{array}{l}\text { Reporting } \\
\text { Schedule }\end{array}$ & Data Source & Disaggregation \\
\hline 3.1 & Number of veterinary Services Infrastructures & Annual & MARF's DVS, and SMARF's DVS & States and National MARF's DVS \\
\hline 3.2 & $\begin{array}{l}\text { Number of veterinarians recruited, Vet. Assistants, livestock } \\
\text { extension officer, stockmen and CAHW trained }\end{array}$ & Annual & MARF's DVS, and SMARF's DVS & States and National MARF's DVS \\
\hline 3.3 & $\begin{array}{l}\text { Number of Animal Health Research and Veterinary } \\
\text { Services Projects established }\end{array}$ & Annual & MARF & MARF's DVS \\
\hline 3.4 & Number of veterinary Services marketing Infrastructures & Annual & MARF's DVS, and SMARF's DVS & MARF's and SMARF's DVS \\
\hline 3.5 & Number of Veterinary research Projects & Annual & MARF's DVS, and SMARF's DVS & MARF's and SMARF's DVS \\
\hline 3.6 & Number of veterinary Services Progress reports submitted & Annual & MARF's DVS, and SMARF's DVS & MARF's and SMARF's DVS \\
\hline 3.7 & Number of Livestock credit facilities & Annual & MARF's DVS, and SMARF's DVS & MARF's and SMARF's DVS \\
\hline
\end{tabular}

\section{Animal health performance data}

Input: Expenses, vet infrastructure (equipment, clinics, labs, manpower, etc.)

Output: Number of livestock vaccinated, dip constructed, CAHW trained etc.

Outcome/impact:

I. Number of livestock farmers receiving veterinary services

II. Increase in milk, meat, eggs, quality skin and hides a result of veterinary services delivery

III. Decrease in livestock mortality rate due to NVS

IV.Increase in farmers' income as a result of NVS

Input: Animal health data, number of Veterinarians, Stockmen, CAHW/county/boma etc.

I. Output: Mobile clinics, livestock extension officers/state

II. Total number of cattle dip/sate

III. Total number of trained pastoralist, CAHW/state

Outcome/impact:

I. Number of CAHW per county

II. Total milk, meat, eggs produced/state

III. Overall change in pastoralist income

IV.Value of livestock export

The financial information can be reported using the normal government financial system.

\subsubsection{Veterinary Services Project Data}

Veterinary Services Projects' data, represents information collected from animal health and veterinary services related projects. Information and data are to be collected by management of the concerned project or NGOs, reflecting the state or agro-ecological zones of their operation, collated and presented in their progress reports with subsequent presentation to the MARFS's DVS and the stakeholders.
Standard reporting format may be designed for each project by the National Directorates of Veterinary Services and that of Planning, and it should capture the outcome and impact of the project and addresses the change within the project.

\subsection{Data Collection}

Standard data collection and reporting system has to be developed by all the key stakeholders (MARF's DVS, Directorate of Livestock Extension, SMARF, CAHWs) with the aim to compose periodical monitoring data system, in a very integrated format (Animal Health System). However, animal health survey may be disaggregated into county, state and nation or on pastoralist system and agro-ecological zones. Some subsectors may have special system for the data collection, which may reflect their nature, state or agroecological zones. Such data should include the following:

I. Animal disease reporting and forecasting;

II. Livestock disease surveillance and diagnosis (disease control);

III. Trans-boundary and border post reporting;

IV.Livestock marketing, and

V. Researching on animal health.

The frequency of disease and the national livestock census/pastoralist surveys have to be determined, it worthy of note that some surveys may take longer time but with more reliable information on animal health and DVS outcome.

\subsection{Data, Baseline, Dissemination and Use}

Monitoring and evaluation of Veterinary Services performance against the MARF's strategic objectives using each indicator will have to seek answers for the following questions: 
1) What is measured and the relevance of the indicator?

2) How far the states have gone into addressing veterinary services' or animal health status and how do they compare?

3) What is being done?

4) What do stakeholders do?

It could be helpful if the current status along with the trend be compared in order to examine the course of change, such that stakeholders are kept informed about the causes for alarm. However, the data sources for monitoring may be generated through a survey (primary or secondary data) and the following methodologies could be explored:

I. Questionnaires (guided questions) to be administered in the field for collection of the necessary primary information as per the subject or indicator;

II. Observations and Rapid Rural Appraisals Techniques could be applied during the field visit;

III. If need be, necessary samplings techniques could also be applied given the size of the population, and

IV.Secondary data will have to be gathered from documents and records pertaining to the subject matter or any relevant literature.

In the absence of baseline data, a pilot survey may be carried out at national, state and county levels, or in accordance with agro-pastoral zones. A consistent data could serve as a baseline data and as a reference point for monitoring change and impact assessment. However, data collected during years of calamities (such as disease outbreak, drought or flood) may not serve as a base year, given that the baseline data may be biased.

The M\&E generated data are subjected to analysis and interpretation, the generated information is then used for decision-making. Data interpretation has to be in a clear format, in simple plain language, accessible to policy and decision makers and all the stakeholders. For adequate data analysis, appropriate statistical techniques for data analysis to generate scientific findings for appropriate measures or actions can be used, however, statistical analysis that provides estimate can be used to analyze veterinary services coverage, trend in livestock performance and livestock health system performance.

Essentially, indicators are M\&E's tools that measure or track a change per time compared to a baseline data and are expressed as indices. Whilst an index is a sum up of figures per year, it also shows how much a figure for one year change differs from that of another year. However a chain of index shows whether the rates of change are constant, increasing, decreasing and the extent of the yearly variation (10).

\subsection{Assessments and Reviews}

The National Veterinary Policy or Veterinary Services could be assessed and reviewed based on set of policies, previously collected reports and results of survey, and the assessment may involve the following reviews:

\subsubsection{Joint Implementation Review}

The review should be jointly undertaken by DVS and animal health development partners, with sole purpose to annually produce inputs to the key MARF's animal health management. The Join Implementation Review should review progress, review implementation and evaluate the progress of the programs, as well as, examine achievements and challenges in delivering veterinary services by public and private veterinarian or CAHWs to pastoralists, agropastoralists and livestock farmers.

\subsubsection{Animal Health Expenditure Review}

The animal health expenditure review can be conducted annually by the MARF's relevant Directorates such as Veterinary Services, Livestock Extension, Planning, Finance and Human Resources, Investment and Marketing, to assess the delivery of veterinary services and animal health performance in terms of progress, constrain, policy analysis and institutional reform. Basically, it endeavors to provide input to the MARF's Directorate of Veterinary Services.

\subsubsection{Budgetary and Development Fund Review}

There should be a periodically/quarterly review and assessment of the capital grant or any funding relevant to the implementation of the National Directorate of Veterinary Services and the results should be used for monitoring and evaluation.

\subsection{Reporting Format}

Monitoring and evaluation should be well focused, manageable and allows for cross-cutting comparison which could form the bases for selection of short-term indicators which in turn should monitor animal health progress that aligns with hunger reduction, food and nutrition insecurity reduction, through livestock health and growth enhancement.

Monitoring and evaluation reporting on veterinary services, livestock growth performance can be undertaken either annually or periodically (biannually or quarterly). But, as far as MARF's Policy Framework and Strategic Plans are concerned, monitoring report on veterinary services performances can be done yearly to evaluate DVS performance against each of the strategic objective and could include a brief description of the indictor and the status of the indicator statement (using charts to show trends) which is to be measured against policies and strategic objectives. However, the timeframe for the dissemination of the information has to be planned to match with planning cycles and needs of all the stakeholders.

\subsection{Annual Reviews and Schedule Meetings}

Monitoring and evaluation entails key monitoring and review meetings, the following calendar serves as an example. 
Table 6. Calendar for Key Monitoring and Review Schedule Meetings.

\begin{tabular}{|c|c|c|c|c|c|c|c|c|c|c|c|}
\hline \multirow{2}{*}{ Review and Assessment Meeting } & \multicolumn{11}{|c|}{ One Calendar Year } \\
\hline & $\begin{array}{ll} & 2 \\
\end{array}$ & 3 & 4 & 5 & 6 & 7 & 8 & 9 & 10 & 11 & 12 \\
\hline \multicolumn{12}{|l|}{ DGs MARF and SMARF Meeting } \\
\hline \multicolumn{12}{|c|}{ Vet Services Assessment and Reviews Meeting } \\
\hline \multicolumn{12}{|l|}{ Quarterly Technical Review } \\
\hline \multicolumn{12}{|l|}{ Annual Veterinary Services Review } \\
\hline \multicolumn{12}{|c|}{ Animal Health Stakeholders' Implementations Review } \\
\hline \multicolumn{12}{|c|}{ Veterinary Services and Public Expenditure } \\
\hline Livestock Development Fund & & & & & & & & & & & \\
\hline
\end{tabular}

\section{Institutional Adjustment or Arrangement}

Duties and responsibilities associated with monitoring and evaluation of the National Veterinary Policy implementation are presented in Table 7. As depicted in Figure 2, monitoring team should make sure that they use transparent, pre-agreed measurements when judging performance [22]. It is worth noting here that, the list is non-exhaustive and subject to the Directorate of Veterinary Service Strategic Plan objectives, monitoring and evaluation themes, development partners, governmental and non-governmental stakeholders.

Table 7. Monitoring and Evaluation Framework for the South Sudan National Veterinary Policy.

\begin{tabular}{|c|c|}
\hline Working Group & Monitoring and Evaluation Responsibilities/ Officer-in-Charge \\
\hline NVP M\&E Thematic Body & $\begin{array}{l}\text { 1) Setting-up a functional NVP Framework and its review } \\
\text { 2) Develop M\&E guidelines and its review } \\
\text { 3) Enhance and disseminate veterinary services data } \\
\text { 4) Aiding National Bureau of Statistic in conducting livestock census } \\
\text { 5) Generate data for veterinary services indicators and compile veterinary services plan performances } \\
\text { Officer-in-Charge: DG of Veterinary Services/Chair of the NVP M\&E Thematic Body }\end{array}$ \\
\hline MARF's DVS & $\begin{array}{l}\text { 1) Monitor the implementation of National Veterinary Policy. } \\
\text { 2) Facilitate the SMARF Department of Veterinary Services to undertake technical reporting. Endorse the data submitted } \\
\text { by the states. Provision of feedback reporting to SMARF Department of Veterinary Services. } \\
\text { 3) Collate quarterly physical and financial progress reports. Conduct periodical National Veterinary policy review meetings. } \\
\text { Officer-in-Charge: MARF's Under-Secretary and DG for Veterinary Services }\end{array}$ \\
\hline $\begin{array}{l}\text { States Counties Veterinary } \\
\text { Services Administration }\end{array}$ & $\begin{array}{l}\text { Collate data and prepare state report and submit them periodically to MARF. Monitor National Veterinary Policy related } \\
\text { activities in the state, as well as, collection of veterinary services related project input, output and include them into state's } \\
\text { physical and financial quarterly progress reports. } \\
\text { Officer-in-Charge: SMARF's Director/DG for Veterinary Services } \\
\text { Monitor disease emergence at county, bayam and boma. Complete disease surveillance reporting form and submit to the } \\
\text { State MARF. } \\
\text { Officer-in-Charge: Chairperson of M\&E Thematic Working Group }\end{array}$ \\
\hline $\begin{array}{l}\text { Pastoralist, Livestock farmers } \\
\text { and Fisher-folk Unions and } \\
\text { CAHWs }\end{array}$ & $\begin{array}{l}\text { Monitor disease emergence at county, bayam and boma. Complete disease surveillance reporting form and submit to the } \\
\text { State MARF. } \\
\text { Officer-in-Charge: Chairs of the Pastoralist, Livestock farmers and Fisher-fork Unions } \\
\text { 1) Decide on capital transfer based on budget, work plans, infrastructural, technical and financial report }\end{array}$ \\
\hline $\begin{array}{l}\text { MARF's Directorate of } \\
\text { Finance }\end{array}$ & $\begin{array}{l}\text { 2) Monitor the performance and progress of veterinary services } \\
\text { 3) Review audit reports and take action on veterinary services funding } \\
\text { Officer-in-Charge: MARF's Under-Secretary }\end{array}$ \\
\hline $\begin{array}{l}\text { Animal Resources and } \\
\text { Fisheries Lead } \\
\text { Ministries/Directorates } \\
\text { Boards of Under-Secretaries }\end{array}$ & $\begin{array}{l}\text { Supervise technical and financial implementation, as well as, implementation of cross-cutting activities and review } \\
\text { livestock sector reports on programme implementation. } \\
\text { Officer-in-Charge: MARF's DG for Finance }\end{array}$ \\
\hline $\begin{array}{l}\text { Animal Resources and } \\
\text { Fisheries Lead Directorates }\end{array}$ & $\begin{array}{l}\text { 1) To lead M\&E functions (NVP and SMARF performance assessment). } \\
\text { 2) Review reports on State's component of veterinary services and to report on national component. } \\
\text { 3) Collation of data to monitor NVP implementation and regular monitoring reporting the Economic Cluster. } \\
\text { 4) Examination of livestock sector of the economy performance at national level. } \\
\text { 5) Enhance the capacity of Veterinary Services staff and planners in comprehending M\&E practices. } \\
\text { Officer-in-Charge: MARF's DG for Veterinary Services/ Planning }\end{array}$ \\
\hline $\begin{array}{l}\text { National Bureau of Statistics, } \\
\text { RSS }\end{array}$ & $\begin{array}{l}\text { Collaborate with the South Sudan Center for Census Statistic and Evaluation in undertaking National Livestock census. } \\
\text { Officer-in-Charge: MARF's DGs for Veterinary Services/ Animal Production, Extension and Planning }\end{array}$ \\
\hline $\begin{array}{l}\text { Development Partners and } \\
\text { NGOs }\end{array}$ & $\begin{array}{l}\text { 1) Participate in monitoring livestock programs and the national veterinary policy implementations. } \\
\text { 2) Participate in M\&E themes working group and in the National Veterinary Policy reviews. } \\
\text { Officer-in-Charge: Chairs of the Pastoralist, Livestock farmers and Fisher-fork Unions }\end{array}$ \\
\hline
\end{tabular}


In addition, the enhancement of the data quality and analysis, a Veterinary Statistic Unit have to be established at both national and states levels, which in turn shall foster information culture amongst the staff and promote information demand and use between states and the national DVS.

The Veterinary Statistic Unit shall be pivotal in linking data to budget allocation and the development of indicator-driven planning, such that the processes of data quality is used within the planning process. Similarly, veterinary services performance report could be compared with other sectors within livestock industry, as it will provide strategic interventions needed to improve veterinary services delivery, as well as, to accelerate growth and development of the livestock industry.

\section{Conclusion}

Monitoring and evaluation framework for the NVP provides a process for measuring progress in delivering veterinary services. It underscore that NVP could be implemented with a view of learning and correcting at the same time. Evaluation involved progress review, effect prediction and identification of essential adjustment in veterinary policy. It answers a question, as to whether DVS and animal health actors are meeting their goals or not and how could be improved. Hence, monitoring and evaluation framework for the NVP should be seen as an integral part of the budgeted policy framework and strategic plan of the DVS, and as a system that review progress, identify challenges and make a difference.

The scope of the framework for monitoring and evaluation addresses measurement of NVP performance, data collection and analysis, reporting, reviews and institutional arrangement. While, its operationalization was to be based on the logical approach of inputs, process, output, outcomes and impact indicators. The framework also associated indicators with the sources of data and it reflected veterinary services inputs in terms of outputs, outcomes and impact. It also addressed the need for data quality assurance, disaggregation, data synthesis, analysis, results dissemination and utilization.

The framework also depicted veterinary services' performance indicators that are considered crucial in informing livestock stakeholders about the trend in animal health status, the course of action that could improve the performance of veterinary services, the status of animal health, livestock health performance and its contribution to livestock growth, poverty reduction, pastoralists' welfare and the national economy.

The M\&E Framework of the NVP suggests that veterinary services and livestock growth performance reporting, could be reported either annually or periodically and that the dissemination of the information should be matched with the planning cycles and needs of all the stakeholders. It designated duties and responsibilities in implementation of monitoring and evaluation to MARF's DVS, and for the enhancement of data quality, the framework realized the necessity of Veterinary Statistic Unit to be established, to foster information culture and promote information demand.

\section{References}

[1] Ministry of Animal Resources and Fisheries. (2012). Policy Framework and Strategic Plans 2012 - 2016. MARF Republic of South Sudan.

[2] Cuellar, M. J. (2013). The Nature of Project Success. http://works.bepress.com/michael_cuellar/24.

[3] Hwang, B. and Lim, E. (2013). "Critical Success Factors for Key Project Players and Objectives: Case Study of Singapore." J. Constr. Eng. Manage., 139 (2), 204-215.

[4] Kamau, C. G. and Bin Mohamed, H. (2015). Efficacy of Monitoring and Evaluation Function in Achieving Project Success in Kenya: A Conceptual Framework. Science Journal of Business and Management. 3 (3): 82-94.

[5] Mbiti, V. M. and Kiruja, E. (2015). Role of monitoring and evaluation on performance of public organization projects in kenya: a case of kenya meat Commission. International Journal of Innovative Development \& Policy Studies. 3 (3): 12-27.

[6] Craig, B. C., Shaker, R. R. and Das, R. (2018). A review of approaches for monitoring and evaluation of urban climate resilience initiatives. Environment, Development and Sustainability. 20: 23-40.

[7] National Veterinary Plan. (2012). MARF NVP Republic of South Sudan, 2012 - 2014 (August. 2012).

[8] MARF, RSS. (2012). First national livestock and fisheries coordination conference on policy framework and strategic plans (2012 - 2016), under the theme: Effective Policy and Strategic Planning for the Development of Livestock and Fisheries Industry in South Sudan. Juba bridge hotel, Juba, $28^{\text {th }}-31^{\text {st }}$ may 2012. Conference Proceedings Report.

[9] Kanisio, J. O., Legge, M. R. K., Nasona, M. G., Samuel, K., Legge, M. S., Penaflor, P. E. and Poleslico, R. V. (2011). The joint baseline survey report on agriculture and animal resources in Southern Sudan. The MAF and MARF Technical Committee. IFAD/EKE.

[10] OIE. (2012). World Organisation for Animal Health. Terrestrial Animal Health Standard Commission Report. March 2008. Evaluation of Veterinary Services. Terrestrial Manual 7th Edition, 2012. Volumes 1 M. Young, the Technical Writer's Handbook. Mill Valley, CA: University Science, 198.

[11] NALEP. (2011). National Agriculture and Livestock Extension Policy Agricultural and Livestock Extension Task Force. Juba. South Sudan Ministry of Agriculture and Forestry, Ministry of Animal Resources and Fisheries, GRSS.

[12] Taban, Y. T and Lako, C. L. A. (2012). Assessment of staff distribution and resources allocation in relation to the efficient and effective delivery of veterinary services in the Republic of South Sudan. Comprehensive Final Report. Dierenartsen Veterinaires Zonder Grenzen sans Frontieres Belgium.

[13] Catley, A. (1999). Monitoring and impact assessment of community-based animal health projectsin Southern Sudan. Towards participatory approaches and methods. A report for Veterinaires Sans Frontieres Belgium and Veterinaires Sans Frontieres Switzerland. 
[14] AU/NEPAD. (2010). The New Partnership for Africa's Development (NEPAD) Agency of the African Union (AU/NEPAD) www.nepad.org.

[15] Michael B. Mascia, M. B., Pailler, S., Thieme, M. L., Rowe, A., Bottrill, M. C., Danielsen, F., Geldmann, J., Naidoo, R., Pullin, A. S. and Burgess, N. D. (2014). Commonalities and complementarities among approaches to conservation monitoring and evaluation. Biological Conservation. 169: 28267.

[16] Hassan, A. I. (2013). AnInvestigation of Structural Capacityas a Component of Monitoring and Evaluation in Project Success of Road Construction Projects in Kenya. International Journal of Academic Research in Business and Social Sciences., 3: (8), 443-452.

[17] Kariungi, S. M. (2014). Determinants of Timely Completion of Projects in Kenya: A Case of Kenya Power and Lighting Company, Thika. ABC Journal of Advanced Research., 3 (2): 9-19.

[18] Olubode, O. O., Chilonda, Q., Minde, I. and Bhat, Y. (2008). Working Paper 24. Indicators for M\&E of agricultural performance and shared goals southern Africa. Regional
Strategic Analysis and Knowledge Support System. www.resakss.org.

[19] IFAD. (2012). Managing for Impact in Rural development. A Guide for Project M\&E. IFAD, International Fund for Agricultural Development. www.ifad.org'.

[20] WHO. (2010). Monitoring and Evaluation of health systems strengthening. An operational Framework. WHO, Geneva. Oct 2010 .

[21] FAO. (2011). Sustainable animal health and contained animal related human health risks in support of the emerging onehealth agenda. Applying lessons learned from highly pathogenic avian influenza in the prevention and containment of major animal diseases and related human health risks. FAO progamme Committee, Hundred and Sixteen Session.www.fao.org.

[22] Chapman, A. (2014). "Project management, tools, process, plans and project planning tips". http://www.businessballs.com/project.htm, accessed 8-3. 